\title{
US government moves science to the forefront
}

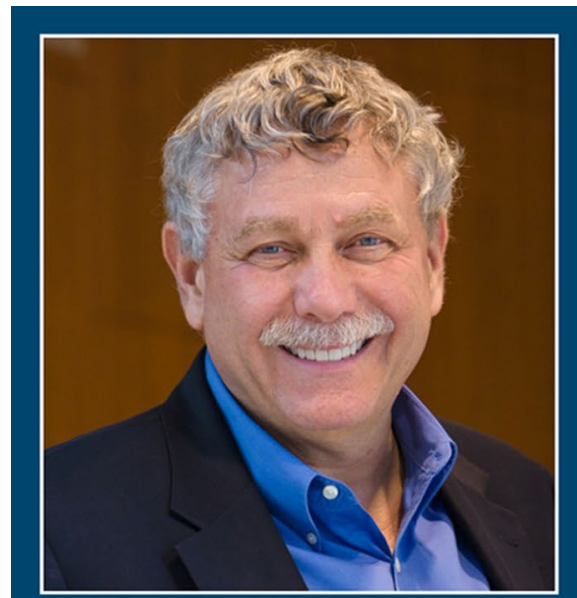

Eric Lander, Presidential Science Advisor-designate

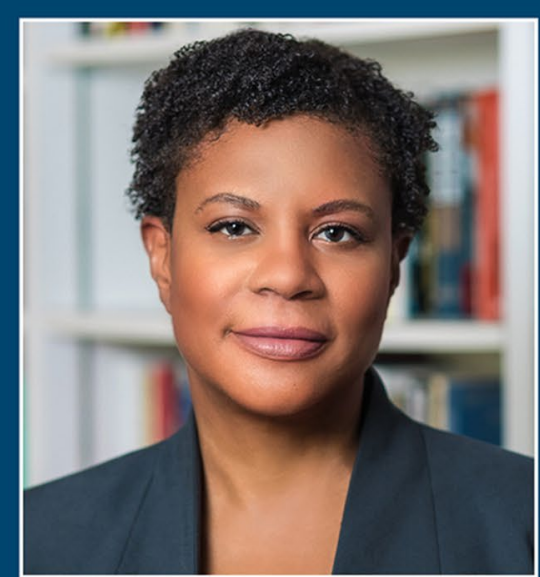

Alondra Nelson, OSTP Deputy Director for Science and Society

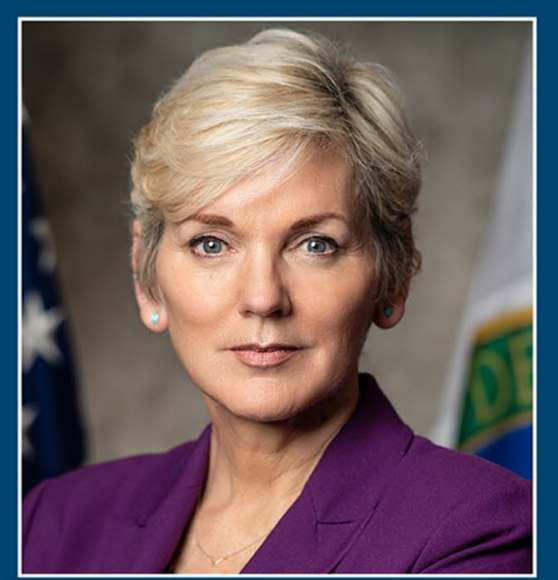

Jennifer M. Granholm, Secretary of Energy
$\mathrm{F}$ or the first time, the US presidential administration has created a cabinet position for the science advisor. Naming his science team before the presidential inauguration on January 20, 2021, President Joe Biden expects the scientists to "help the Biden-Harris administration confront some of the biggest crises and challenges of our time, from climate change and the impact of technology on society to pandemics, racial inequity, and the current historic economic downturn," according to the news release. Eric Lander is the Presidential Science Advisor-designate and nominee for Director of the Office of Science and Technology Policy (OSTP). Lander was a principal leader of the Human Genome Project and has been a pioneer in the field of genomic medicine.

Alan J. Hurd, a former president of the Materials Research Society, supports a direct channel of communication from the science advisor to the White House.
When Hurd served as a Franklin Fellow at the US State Department, where he supported the Science and Technology Advisor to the Secretary of State from 2012 to 2013 , he says that then science advisor John Holdren was welcomed as an observer during Cabinet meetings. Hurd credits their scientific input with strengthening Interagency Working Groups (IWGs) such as the IWG for the National Nanotechnology Initiative and Nanomedicine R\&D.

In another first, Biden created a position in OSTP for society and science. Named to the office of OSTP Deputy Director for Science and Society is Alondra Nelson, a distinguished scholar of science, technology, social inequality, and race, who serves as president of the Social Science Research Council, an independent, nonprofit organization linking social science research to practice and policy.

Just seven days after the presidential inauguration, Biden signed an executive order that establishes the office of a Chief Science Officer for every agency that oversees, directs, or funds scientific research. According to a news release, the agencies are tasked with designating a senior agency employee as Chief Science Officer to ensure agency research programs are scientifically and technologically well founded and conducted with integrity.

Moreover, Biden's executive order remarks that because science, facts, and evidence are vital to addressing policy and programmatic issues across the federal government, all agencies - not just those that fund, conduct, or oversee scientific research-must designate a senior career employee as the agency's Scientific Integrity Official to oversee implementation and iterative improvement of scientific-integrity policies and processes, according to the news release.

"Science will always be at the forefront of my administration - and these

Eric Lander (photo credit: Casey Atkins Photography, courtesy of Broad Institute); Alondra Nelson (photo credit: http://www.alondranelson. com/); and Jennifer M. Granholm (photo credit: US Department of Energy). 
world-renowned scientists will ensure everything we do is grounded in science, facts, and the truth," says Biden in a news release.

"From the coronavirus pandemic to our climate crisis, this past year has reaffirmed the importance of listening to scientists when it comes to meeting the unprecedented challenges facing the American people," says Vice President Kamala Harris in the news release.

\section{President's Council of Advisors on Science and Technology}

Within the realm of OSTP, the BidenHarris administration revives the President's Council of Advisors on Science and Technology (PCAST) with Nobel Laureate Frances H. Arnold and Massachusetts Institute of Technology's Vice President for Research and E.A. Griswold Professor of Geophysics Maria Zuber as co-chairs. An expert in protein engineering at the California Institute of Technology, Arnold is the first woman in the United States to receive the Nobel Prize in Chemistry. Zuber, an expert in geophysics and planetary science, is the first woman to lead a NASA spacecraft mission and has chaired the National Science Board. They are now the first women to serve as co-chairs of PCAST.

PCAST - co-chaired also by the director of OSTP-will advise the administration on policy that affects science, technology, and innovation. The Council will also advise the president on scientific and technical information that is needed to inform public policy relating to the economy, worker empowerment, education, energy, environment, public health, national and homeland security, racial equity, and other topics.

\section{US Department of Energy (DOE) and materials science}

During her confirmation hearing for Secretary of Energy at the US Senate Committee on Energy and Natural Resources, Jennifer M. Granholmthe former governor of the state of Michigan-said that when the auto industry in her state went bankrupt, "I knew we had to diversify, both inside and outside the auto industry. When I say 'inside' the auto industry, I mean we had to make car 2.0: the electric vehicle, including the guts to that vehicle, the battery. And diversifying outside the auto industry, we had to create jobs in new sectors. The most promising of those sectors was in clean energy." She said that, now, Michigan is one of the top five states for patents in clean energy.

The Energy Act of 2020 was underscored during the hearing. This bipartisan, bicameral legislation that made it into the Omnibus bill signed on December 27, 2020, represents several years of negotiations with Senate leaders Joe Manchin (D-W.Va.) and Lisa Murkowksi (R-Alaska). "This all-of-the-above energy package is the first comprehensive national energy policy update in 13 years," says Manchin in a news release. "The Energy Act of 2020 provides a down payment on the technologies that will be critical to reducing greenhouse gas emissions in the power sector, industry, and buildings and addressing climate change."

Murkowski agrees. "The Energy Act represents the first modernization of our nation's energy policies in well over a decade," she says in a news release. "This bipartisan package will foster innovation across the board on a range of technologies that are critical to our energy and national security, our long-term economic competitiveness, and the protection of our environment," she said.

The Energy Act focuses on energy storage; advanced nuclear energy; carbon capture, utilization, and storage; carbon removal; renewable energy; critical minerals and materials; fusion energy; industrial technologies; smart manufacturing; and grid modernization, among other areas. It reauthorizes the Advanced Research Projects Agency-Energy (ARPA-E) program, which Granholm acknowledged during the hearing stating awareness of
ARPA-E's funding support for R\&D in $\mathrm{CO}_{2}$ sequestration coupled with sustainable mining efforts.

Along with carbon capture, Granholm emphasized R\&D and demonstration interests in the critical minerals supply chain, advanced nuclear and hydro power, and energy-storage technology. She also emphasized the role of DOE as a leader in machine learning in order to accelerate R\&D. "I am aware," she said, "that DOE has recently accelerated the use of machine learning and other highperformance computing tools in the development of next-generation battery technology and manufacturing to bring down the cost of batteries, improve their performance, and reduce the use of critical materials."

Granholm pledged to follow through on clean energy and to move various energy projects to commercialization with the assistance of the private sector engagement throughout the process. Her appointment was confirmed on Februray 25, 2021.

Materials scientist Vanessa $Z$. Chan is appointed as Chief Commercialization Officer and Director of the Office of Technology Transitions at DOE. She comes to the Biden-Harris administration from the University of Pennsylvania where she was the Jonathan and Linda Brassington Professor of Practice in Innovation \& Entrepreneurship and the Undergraduate Chair of the Materials Science and Engineering Department. She has spent the past 20 years helping large companies commercialize their technologies and revamping the academic curriculum of engineering students to make a greater social impact. Chan earned her $\mathrm{PhD}$ degree in materials science and engineering from the Massachusetts Institute of Technology.

Materials scientist Tanya Das has been appointed Chief of Staff for the DOE Office of Science. Das was most recently a professional staff member on the US House Committee on Science, Space, and Technology, where she worked on legislation on a range 
of issues in clean energy and manufacturing policy. Before arriving on "the Hill," Das was a research assistant in Jon Schuller's group at the University of California, Santa Barbara, where she studied light-matter interactions at the nanoscale. She established a "local field theory" approach to understanding the multipolar resonances of spherical nanoparticles, and has used this to develop novel computation time-saving techniques for running finite-difference time-domain electromagnetics simulations.

In her role as Chief of Staff, Das oversees the day-to-day operations of the Office of Science. "It is my responsibility to ensure that the work we do across our scientific portfolio-including a substantial investment in new materials development and the basic science that underpins it - meets the needs and expectations established in the president's budget," she says, "and to help reflect the needs and expectations of the research community to my colleagues in the administration."

In line with the Biden-Harris administration, Das told MRS Bulletin that the Office of Science will implement the administration's priorities that include a focus on climate change, clean energy, and economic growth, but also diversity, equity, and inclusion as well. In reference to the inaugural office of Deputy Director for Science and Society in OSTP, Das says, "The Biden-Harris administration is committed to making sure that the best social science research underpins our efforts to ensure that science is diverse and inclusive, and to best understand the societal implications of science and technology policy."

Acknowledging DOE's Scientific Integrity Policy document, Das told MRS Bulletin, "Consistent with the guidance of President Biden's Memorandum on Restoring Trust in Government Through Scientific Integrity and Evidence-Based Policymaking [signed on January 27, 2021], DOE will identify a Scientific Integrity Officer who will be responsible for reviewing this policy, and ensuring that departmental decisions are based on the best available scientific data, and that our findings are never distorted by political considerations."

Judy Meiksin 